\title{
School subject choices and social class differences in entry to higher education - Comparing Scotland and Ireland
}

\author{
Markus Klein, Cristina Iannelli, Emer Smyth
}

\section{INTRODUCTION}

The existing literature on differentiation in secondary education and its consequences for social inequalities in educational attainment has mainly focused on students' assignment into different formal school tracks (e.g. Bol et al. 2014; Brunello and Checchi 2007; Hanushek and Wößmann 2006; Horn 2009; Horn 2013). With a few exceptions (Ayalon 2006; Iannelli 2013; Van de Werfhorst, Sullivan and Cheung 2003), social stratification research has largely neglected the role of internal differentiation within secondary schools, such as allocation to, or take-up of, different subjects, in shaping social inequalities in life course outcomes.

We advance the literature on curriculum differentiation by analysing whether specific subject choices in upper secondary education mediate social inequalities in higher education (HE) entry in Scotland and Ireland. Both countries are distinct in the extent to which students are limited in their subject choices and in the requirements for HE entry. This distinction can give us valuable insights into the extent to which the mediating role of subject choice for social class differences in HE entry is shaped by the opportunities offered by the education system. Since both Scotland and Ireland experienced a large expansion of higher education (Iannelli, Gamoran and Paterson 2011; McCoy and Smyth 2011), a further aim of our study is to identify changes in the mediating effect of subject choice for social class differences in entering HE across different cohorts of school leavers.

In the following section we will describe the educational systems in Scotland and Ireland and derive some hypotheses about how country differences in curriculum differentiation and $\mathrm{HE}$ requirements affect social inequalities in HE. Then we will describe the data, variables and our analytic strategy before presenting the results. The chapter ends with a 'conclusion' section which discusses the results in light of our hypotheses.

\section{THE SCOTTISH AND IRISH EDUCATION SYSTEMS}

\section{Scotland}

Secondary education in Scotland starts at age 12 and lasts for six years (from S1 to S6). Schooling is compulsory until the age of 16 . In the final two years of compulsory school (S3/S4), students prepare for examinations, known as Standard Grades. ${ }^{1}$ These examinations can be taken at different levels of 
This is a draft chapter. The final version is available in Models of Secondary Education and Social Inequality : An International Comparison edited by Blossfeld, H., Buchholz, S., Skopek, J., Triventi, M., published in 2016 by Edward Elgar Publishing Ltd. The material cannot be used for any other purpose without further permission of the publisher, and is for private use only.

difficulty (Foundation, General and Credit). These levels were introduced in the 1980s to support the increasing numbers of pupils staying in education up to age 16 (OECD 2007).

In post-compulsory schooling, students take subject-specific Highers exams in S5 or S6. In addition, they can take exams at Intermediate 2, a level in between Standard Grades and Highers, and Advanced Highers, mostly taken in the final year of secondary school (S6). The curriculum is mainly academic in nature, with vocational studies mainly delivered through links with Further Education (FE) Colleges. Moreover, there are no compulsory subjects. Students can choose not only the type of subjects, but also the number of subjects, they want to study.

The main differentiation among Scottish schools is between private ("independent") and public schools. Private schools are privately owned, charge fees and test students prior to admission. Therefore they have a more selective character both socially and academically. Schools can further be differentiated into denominational (mostly Catholic) and non-denominational schools. Denominational schools are state-funded and follow the same curriculum as the other nondenominational schools.

Students who aim to go to university have to submit a single on-line application via the Universities and Colleges Admissions Service (UCAS) specifying a list of up to five courses and the institutions providing them for which they are applying. The application is then forwarded by UCAS to the chosen institutions, which decide whether to make an offer of a place. In Scotland, as in the rest of the UK, there are no statutory requirements in terms of number and type of subjects for gaining access to HE institutions (OECD 2007). Nevertheless, universities expect that prospective university candidates have sat between three and five Highers in their fifth or sixth year of secondary schooling. Beside the number of Highers (or Advanced Highers), UK universities, and particularly the researchintensive universities (the Russell Group universities), take secondary school subjects and grades achieved within these subjects into account in their decisions to make an offer. Recently, the Russell Group universities published a dossier that identified eight subjects (English, Maths, Languages, Physics, Chemistry, Biology, Geography and History) as "facilitating" access to their institutions (Russell Group 2011).

\section{Ireland}

As in Scotland, Ireland has a compulsory school system until the age of 16. Secondary education is divided into two phases: junior cycle (lower secondary), which lasts three years, and senior cycle (upper secondary), which lasts two years, with an optional 'Transition Year' between the two stages. Students take a national examination, the Junior Certificate, at the end of junior cycle, and most students remain in school until the end of senior cycle when they take the Leaving Certificate examination. In this exam, students typically take between six and eight subjects, usually seven. All 
students are required to take English and Maths. Students are required to study Irish, unless they have received their primary education outside the State or are granted an exemption because of learning difficulties. All Leaving Certificate subjects can be studied at Higher or Ordinary level, with the exception of Civic, Social and Personal Education which is taken at common level. In addition, Maths and Irish can be taken at a lower, Foundation level.

There are three kinds of secondary schools in Ireland: voluntary secondary schools, largely privately owned but publicly funded (with the exception of a small fee-paying sector) and denominational in character; vocational schools set up originally to cater for working-class students; and community/comprehensive schools established to bridge the gap between academic voluntary secondary schools and vocational schools. Although the three sectors continue to differ in management and funding structures, they operate within the same curriculum and assessment framework.

Entry to higher education is largely determined by grades in the Leaving Certificate exam. At least in theory, all those who take the Leaving Certificate exam can go on to higher education. The exception is a small group (6-7\%) of the cohort who take the Leaving Certificate Applied program; these students cannot enter higher education directly, only indirectly through further education (Post Leaving Certificate) courses. Applications for undergraduate degree and sub-degree courses are centralized nationally through the Central Applications Office (CAO). Students can specify up to 10 choices (in rank order) for degree courses and 10 for sub-degree courses. Students are allocated 'points' on the basis of the grades received and level taken in the exams. The results for the 'best' six subjects are used for the calculation of the final total point-score (no points are allocated for Foundation level subjects). Certain subjects are required for entry for some fields of study but requirements are not very tightly specified - for example, having studied any science subject (including Biology) allows applicants to enter any science degree. The points required for courses reflect the number of places offered and the grade profile of applicants, so the requirements for accessing particular courses varies across institutions and from year to year.

\section{SUBJECT CHOICES AS MEDIATOR OF SOCIAL INEQUALITIES IN HE ENTRANCE}

Despite strong similarities, two striking differences are evident between Scotland and Ireland in the configuration of the education system. First, subject choice in upper secondary education in Scotland has no formal constraints (i.e. there are no compulsory subjects and no restriction in terms of the numbers of subject taken) while in Ireland English, Maths and Irish are compulsory and examinations are generally taken in 6-8 subjects. Second, both the number and type of subjects taken in secondary school are relevant for HE admission in Scotland, while in Ireland HE entry is largely determined by 
This is a draft chapter. The final version is available in Models of Secondary Education and Social Inequality : An International Comparison edited by Blossfeld, H., Buchholz, S., Skopek, J., Triventi, M., published in 2016 by Edward Elgar Publishing Ltd. The material cannot be used for any other purpose without further permission of the publisher, and is for private use only.

grades in the 'best' six subjects irrespective of their type. These differences may have consequences for social inequalities in subject choices which, in turn, may translate into social class differences in HE entry.

Secondary effects of social origin at the time of transition into different educational tracks have been found to be larger in those countries where families can freely make their decision and are not restricted by previous attainment or teacher judgements (Jackson 2013). In similar ways, research has found that systems where there is more freedom of choice of subjects offers more leeway for social differentiation to occur than systems offering a more standardized curriculum (Gamoran 1996).

In an open system of curricular choice like the Scottish one working-class students may choose less demanding subjects or fewer subjects because they are more risk-averse and lack the confidence to succeed (Breen, van de Werfhorst and Jaeger 2014). At the same time, middle-class students may have a stronger interest in particular subject areas, more family support and less fear of failure in relation to core academic subjects such as science or languages than working-class students. The fact that some core academic subjects (the eight "facilitating" subjects) are highly valued for admission to prestigious HE institutions in Scotland may further strengthen social differentiation in subject choice. According to the 'status maintenance' argument (Breen and Goldthorpe 1997), maintaining their parents' status operates as a stronger motivation for higher-class students to take the required subjects for HE admission. Moreover, lower-class students and their parents may also be less familiar with the $\mathrm{HE}$ admission process than higher-class students and parents may simply not know which subjects are relevant for gaining access to HE in general and the more prestigious universities in particular. Given the importance of particular subjects for HE admission, secondary-school curricular choices can be regarded as a way of channeling young people towards, or indeed away from, higher education.

Given these theoretical considerations, our first hypothesis is:

Subject choice in upper secondary education is a stronger mediator for social class differences in HE entry in Scotland than in Ireland. By contrast, school performance mediates social inequalities in Ireland to a larger extent than in Scotland.

\section{SUBJECT CHOICES, SOCIAL INEQUALITIES AND EDUCATIONAL EXPANSION}

During the $1990 \mathrm{~s}$ and the first decade of the $21^{\text {st }}$ century educational expansion has resulted in increasing numbers of students remaining in the school system after compulsory education. Hence, children from different social classes become increasingly alike in terms of educational attainment. However, even when students from lower classes achieve a certain educational level, qualitative differences, such as field of study or type of HE institution attended, matter in the reproduction of 
This is a draft chapter. The final version is available in Models of Secondary Education and Social Inequality : An International Comparison edited by Blossfeld, H., Buchholz, S., Skopek, J., Triventi, M., published in 2016 by Edward Elgar Publishing Ltd. The material cannot be used for any other purpose without further permission of the publisher, and is for private use only.

social inequalities (e.g. Iannelli, Gamoran and Paterson, 2011). Lucas (2001) called this process "Effectively Maintained Inequality (EMI)". One way in which higher-class students in uppersecondary education can remain distinct from lower-class students is to choose those subjects that are particularly required for $\mathrm{HE}$ admission. This strategy not only allows them to differentiate themselves from lower-class students in secondary school but also guarantees long-lasting advantages in later life outcomes (Iannelli 2013). Likewise, HE institutions may have difficulties in selecting appropriate students from the increasing pool of applicants from upper secondary education. This may lead universities to increasingly require higher numbers of core academic subjects for admission to their institutions.

In line with these considerations, our second hypothesis argues:

Over the course of educational expansion, social inequalities in HE entry will be increasingly mediated by secondary-school subject choices, more so in Scotland than in Ireland.

\section{DATA AND METHODS}

For the purpose of our analysis we use a series of Scottish and Irish School Leaver Surveys. The Scottish School Leaver Surveys (1987, 1989, 1991, 1993, 1999, 2001 and 2005) are nationally representative surveys of young people in all kinds of schools except special schools. In order to investigate transitions after compulsory schooling and upper secondary education, students were interviewed two or three times between the ages of 16 and 18/19. The Irish School Leaver Surveys (1980-2007) are nationally representative surveys of young people who left secondary school in the previous academic year. For our analyses, the sample had to be restricted to students who continued in school after compulsory education in both countries. ${ }^{2}$

Our dependent variable is HE entry, indicating whether students enrolled in full-time higher education at the age of 18/19 or not. Our key independent variable, social class of origin, is measured using the European Socio-economic Classification (ESeC) (Rose and Harrison 2010), according to the highest class position among parents: higher salariat class (ESeC 1), lower salariat class $(\mathrm{ESeC} 2)$, intermediate class (ESeC 3-6) and working class (ESeC 7-9). The fifth category "unclassified" comprises all households where both parents are long-term unemployed or have never been employed.

Subject choices in upper secondary education are measured with 12 subject groupings which, for some analyses, we further classify into the two major groups of 'core' and 'other' subjects (following the distinction between 'facilitating' and the other subjects, Russell Group, 2011). 'Core' subjects comprise Irish (in the Irish case only), English, Languages, Maths, Biology, Chemistry, Physics, Geography and History. 'Other' subject groups comprise Business studies (e.g. management, accountancy or bookkeeping), Technology (e.g. engineering, wood work or metal work.), Arts and 
This is a draft chapter. The final version is available in Models of Secondary Education and Social Inequality : An International Comparison edited by Blossfeld, H., Buchholz, S., Skopek, J., Triventi, M., published in 2016 by Edward Elgar Publishing Ltd. The material cannot be used for any other purpose without further permission of the publisher, and is for private use only.

Social sciences (e.g. art, music, classical studies or social and political education) and Miscellaneous (e.g. home economics, physical education or religious education).

Performance within subjects is operationalized with a continuous measure, the 'UCAS point score'. UCAS has a tariff system which allows students' grades and level of qualification to be converted into points. Since 2006 UCAS also offers tariff scores for the Irish Leaving Certificate. We standardized the 'UCAS point scores' to compare performance across cohorts and countries.

In order to take school differentiation into account, we control for school characteristics in both countries. In Scotland, we differentiate between private (independent) and state schools and between denominational and non-denominational schools. In Ireland, we distinguish between voluntary secondary schools, vocational schools and community/comprehensive schools. Clusterrobust standard errors are considered in all multivariate analyses to reflect the clustering of young people within schools.

Over time, we differentiate between four cohorts: 1987-1991, 1993, 1999-2001 and 2005. We grouped the years 1987, 1989 and 1991 as well as 1999 and 2001 in order to increase the number of observations. Since polytechnics in the UK were upgraded to universities in 1992, we keep the cohorts 1987-1991 and 1993 separate. Due to a large proportion of missing values related to the information on subjects, we do not use the cohort 1999-2001 for Ireland. Descriptive statistics of our variables are presented in Table 1 in the Supplementary Material (URL).

We conduct all our analyses separately for boys and girls for two main reasons. First, gender differences in subject choices at secondary and tertiary level are well-known (Jin, Muriel and Sibieta 2010; Jonsson 1999; Van de Werfhorst, Sullivan and Cheung 2003). Second, social inequalities in subject choices have been found to differ between men and women (Ma 2009). Hence, there are reasonable grounds to suggest that for boys and girls the mediating role of subject choice for social class differences in HE entry may differ.

It is important to examine the relationship between individual academic ability and curriculum differentiation because prior performance may substantially mediate the association between class of origin and subject choice. Higher-class students may take more demanding subjects than lower-class students just because they tend to perform better in these subjects than the other students. As with formal tracking, we need to disentangle the primary effects from the secondary effects of educational choices. Unfortunately, we do not have information on prior performance in Ireland. Nevertheless, we test for Scotland to what extent prior performance mediates the relationship between social origin and subject choice. Prior performance is measured as the 'unified point score' which, similarly to the 'UCAS point score', summarizes attainment in terms of qualification levels and grades at the end of compulsory schooling (Croxford, Iannelli and Shapira 2007, p. 67) 


\section{RESULTS}

\section{Social origin and subject choice in upper secondary education}

We start our analysis by investigating the relationship between class of origin and subject choice. Table 1 shows the number of 'core' and 'other' subjects by class of origin, separately for boys and girls, in both countries. For both sexes, it is evident that in Scotland higher-class students take, on average, a higher number of 'core' subjects than lower-class students. By contrast, the number of 'other' subjects does not vary by class of origin. Social inequality patterns in Scotland are largely consistent over time for both sexes. The relationship between social origin and number of 'core' subjects only decreased slightly across cohorts. Students from all classes also take, on average, one 'other' subject more over time. For Irish boys and girls, we also find that higher-class students take more 'core' subjects than lower-class students but this relationship is clearly weaker than in Scotland. Since students from all classes take on average approximately the same number of subjects, higherclass students, in turn, take a lower number of 'other' subjects than lower-class students. These social inequalities in the composition of subjects became weaker over time, more so for Irish girls than boys.

[Table 1]

In a next step, we want to identify to what extent prior performance mediates the link between social origin and subject choice. For Scotland, Table 2 shows the results from OLS regressions with number of 'core' subjects as the dependent variable for every cohort and sex separately. ${ }^{3}$ Model 1 considers the association between class of origin and number of 'core' subjects controlling for school characteristics. Model 2 additionally includes the 'unified point score', our measure of prior academic performance. For both sexes, a considerable proportion of social class differences in the number of 'core' subjects taken can be accounted for by prior attainment (e.g. when higher salariat class is compared to working class around $50 \%$ for men and almost $60 \%$ for women). Only for boys does the mediating role of prior school attainment on social inequalities in the number of 'core' subjects become stronger in the youngest cohort (e.g. for higher salariat class vs. working class the increase was from 49\% in 1999-2001 to 64\% in 2005). Nevertheless, in all cohorts and for boys and girls alike, significantly strong advantages of students from higher-salariat class compared to students from the working class remain even after controlling for prior performance (for similar results on previous performance and subject choices in GCSE see McMullin \& Kulic's chapter in this book).

[Table 2]

\section{The mediating role of subject choice for HE entry}

In our multivariate analysis we conduct a series of binary logistic regressions of HE entry for every cohort and both countries separately. In order to compare our estimates of class of origin across 
This is a draft chapter. The final version is available in Models of Secondary Education and Social Inequality : An International Comparison edited by Blossfeld, H., Buchholz, S., Skopek, J., Triventi, M., published in 2016 by Edward Elgar Publishing Ltd. The material cannot be used for any other purpose without further permission of the publisher, and is for private use only.

models, cohorts and two countries, we show average marginal effects which we can interpret as average percentage point differences between classes of origin in the probability of entering higher education. Due to space restrictions we only show the AMEs for the higher salariat class (ESeC 1) in comparison to the working class (ESeC 7-9) across different models in Table 3. For the full tables including all variables see Tables 2-15 in the Supplementary Material (URL).

Our first model (M1) controls only for school characteristics and is our reference model measuring the total effect of class of origin on HE entry. Our second model (M2) controls for the number of 'other' subjects. In the third model (M3) we introduce the number of 'core' subjects. The fourth model (M4) replaces the number of subjects with our single subjects. While the second and third models test whether the total number of subjects in the two main groups accounts for class of origin differences in HE entry, the fourth model tests whether there is further heterogeneity in the broader subject groups which can explain social inequalities in the chances of entering HE. The fifth model (M5) replaces subject dummies with 'UCAS point scores' within subjects and therefore tests the mediating contribution of performance in each subject. The columns "M1-M4" and "M4-M5" additionally indicate the absolute percentage points and the proportion of social class differences explained by subject choice and performance. The column "Unexpl." shows the absolute percentage points and the percentage of the social-class effect that remains unexplained after controlling for our mediating factors.

At the end of the $1980 \mathrm{~s}$, the total effect for the higher-salariat class is very similar for boys and girls in both countries (M1). Students from higher-salariat class background have, on average, a probability that is almost 30 percentage points higher of entering HE than the probability for workingclass students. Across cohorts, social inequalities in HE entry decreased in both countries, particularly among Irish girls. The total effect for higher-salariat class is not significant at the $10 \%$ level for Irish female school-leavers in cohort 2005.

With regard to the mechanisms by which class origin differences are transmitted in HE entry, the results show substantial differences between the countries. In Scotland, the AME for highersalariat class is largely reduced for boys and girls when controlling for the number of 'core' subjects (M3). As expected, the number of 'other' subjects is not a mediating factor for class of origin differences in HE entry (M2). Controlling for single subject dummies also does not add much to the explanation of social inequalities (M4). While differences are slightly reduced when accounting further for attainment (M5), the mediating role of performance is much less pronounced than in the case of subject choice.

[Table 3]

In Ireland, subject choice is a less important mediator for differences between the highersalariat and working classes in HE entry than in Scotland. Nevertheless, a considerable part of social 
inequalities is also mediated by subject choices in Ireland. The composition of subjects rather than the number of subjects seems to be more important in Ireland than in Scotland (see change in the AMEs from M3 to M4). In Ireland, languages, physics and chemistry in particular mediate social inequalities in HE entry (see subject effects in Tables 10-16 in Supplementary Material, URL). Overall performance is a much stronger mediator of class of origin differences in HE entry in Ireland than in Scotland (see results in the column 'M4-M5').

For Scottish boys and girls, the mediating roles of subject choice and performance hardly change over time. In terms of absolute percentage points, we see a slight decrease in the relevance of subject choice over time (see first number in column 'M1-M4'). However, in terms of the proportion of the total effect explained, the mediating role of subject choice remained of equal importance for girls (around 60\%) or slightly increased in the last cohort for boys (see proportion in column 'M1M4'). This increasing relative importance among boys is driven by the fact that 'unobserved' factors decreasingly mediate social inequalities. For Irish boys and girls, both the mediating roles of subject choice and performance decrease, slightly for men and substantially for women (in terms of absolute percentage points). Again, however, the reduction in total effect is largely driven by the decreasing effect of unobserved factors (see reduction of both absolute and relative measures in column 'Unexpl.'). For Irish girls, we see a negative effect of salariat class background when controlling for subject choice and performance in the youngest cohort. Overall, there is no indication that subject choices played an increasing role in mediating social class differences in HE entry over time.

\section{CONCLUSION}

Our aim in this chapter has been to identify the role of subject choice in upper secondary education in mediating social inequalities in HE entry in two distinct education systems, Scotland and Ireland. In Scotland students have no compulsory subjects to sit at the final exams while in Ireland, Maths, English and Irish are compulsory. Moreover, in this latter country students take approximately the same number of subjects and school performance is the major factor taken into account for entry into different HE programs and institutions. In Scotland, instead, there is more variation in the number of subjects taken for the final examinations (Highers) and HE entry is dependent both on the type of subjects studied and the grades achieved in these subjects. Given these differences, we hypothesized that subject choice is a stronger mediator of social class differences in HE entry, while school performance mediates these differences to a larger extent in Ireland.

Our empirical results provide strong evidence for this hypothesis. We have shown that the association between social origin and subject choice is stronger in Scotland than in Ireland. Higherclass students in Scotland take a higher number of subjects regarded as facilitating access to higher education (Russell Group, 2011) than lower-class students. In Ireland, higher-class students also study 
more 'core' subjects (and less 'other subjects') but to a lesser extent than in Scotland. Moreover, in Scotland, social class differences in the number of 'core' subjects taken remain significantly strong even after taking prior performance into account. This indicates that social inequalities in subject choices are not only driven by students' academic abilities but also by the secondary effects of educational choices unrelated to prior attainment. In our subsequent analysis, we found that indeed subject choice is a strong mediator of class-of-origin differences in HE entry in Scotland (a similar result was found in England by McMullin \& Kulic in this book in relation to subject choices in lower secondary education and students' chances of continuing school at upper secondary level). By contrast, performance in upper secondary education more strongly mediates social inequalities in Ireland than in Scotland. These patterns apply to boys and girls. These results have important policy implications. Policies aimed at reducing social inequalities in HE access in Scotland need to provide students from lower social classes with clear information and support in their curriculum decisions. On the other hand, in Ireland raising attainment seems to be the main policy lever for reducing inequalities in HE participation.

Finally, we expected that the mediating role of subject choice for social inequalities in HE entry would become more pronounced over time (our second hypothesis). Our results do not support this hypothesis. In particular in Scotland, subject choice has always been and continues to be a strong mediator for social class differences in HE entry. Interestingly, we find that the total effect of social origin on HE entry decreased over time for both sexes in both countries. This pattern is particularly evident for Irish women. The decline in social inequalities in access to higher education can be largely attributed to the reduction in the proportion of 'unobserved' differences between social groups. This suggests that nowadays in both countries social inequalities can be almost completely explained by differences in subject choice and attainment. 


\section{References}

Ayalon, H. (2006), 'Nonhierarchical Curriculum Differentiation and Inequality in Achievement: A Different Story of More of the Same?', Teachers College Record, 108(6), 1186-213.

Bol, T., Witschge, J., Van de Werfhorst, H. G. and J. Dronkers (2014), 'Curricular Tracking and Central Examinations: Counterbalancing the Impact of Social Background on Student Achievement in 36 Countries.', Social Forces, 94(4),1545-72.

Breen, R. and J. H. Goldthorpe (1997), 'Explaining Educational Differentials: Towards a Formal Rational Action Theory.', Rationality and Society, 9(3),275-305.

Breen, R., van de Werfhorst, H. G. and M. Meier Jaeger (2014), 'Deciding under Doubt: A Theory of Risk Aversion, Time Discounting Preferences, and Educational Decision-Making.', European Sociological Review, 30(2), 258-70.

Brunello, G. and D. Checchi (2007), 'Does School Tracking Affect Equality of Opportunity? New International Evidence.', Economic Policy, 22(52), 781-861.

Croxford, L., Iannelli, C. and M. Shapira (2007), Documentation of the Youth Cohort Time-Series datasets. Study number 5765. Colchester, UK: Economic \& Social Data Service.

Gamoran, A. (1996), 'Curriculum Standardization and Equality of Opportunity in Scottish Secondary Education: 1984-1990.', Sociology of Education, 69(1),1-21.

Hanushek, E. A. and L. Wößmann (2006), 'Does Educational Tracking Affect Performance and Inequality' Differences-in-Differences Evidence Across Countries.', The Economic Journal, 116 (March), C63-C76.

Horn, D. (2009), 'Age of Selection Counts: A Cross-country Analysis of Educational Institutions.', Educational Research and Evaluation: An International Journal on Theory and Practice, 15(4),343-66.

Horn, D. (2013), 'Diverging Performances: The Detrimental Effects of Early Educational Selection on Equality of Opportunity in Hungary.', Research in Social Stratification and Mobility, 32 (June), 25-43.

Iannelli, C. (2013), 'The Role of School Curriculum in Social Mobility.', British Journal of Sociology of Education, 34(5/6), 907-28.

Iannelli, C., Gamoran, A. and L. Paterson (2011), 'Scottish Higher Education, 1987-2001: expansion through diversion.', Oxford Review of Education, 37(6),717-41.

Jackson, M. (ed) (2013), Determined to Succeed? Performance versus Choice in Educational Attainment. Stanford: Stanford University Press.

Jin, W., Muriel, A. and L. Sibieta (2010), 'Subject and course choices at ages 14 and 16 amongst young people in England: Insights from Behavioural Economics.', Research Report DFERR160, London, Department for Education.

Jonsson, J. O. (1999), 'Explaining Sex Differences in Educational Choice: An Empirical Assessment of Rational Choice.', European Sociological Review, 15(4), 391-404.

Lucas, S. R. (2001), 'Effectively Maintained Inequality: Education Transitions, Track Mobility, and Social Background Effects.', American Journal of Sociology, 106(6), 1642-90.

Ma, Y. (2009), 'Pre-College Influences and College Major Choice: Gender, Race/Ethnicity and Nativity Patterning.', Theory in Action, 2(2), 96-122.

McCoy, S. and E. Smyth (2011), 'Higher Education Expansion and Differentiation in the Republic of Ireland', Higher Education, 61(3), 243-260.

OECD (2007), Quality and Equity of Schooling in Scotland. Paris: OECD.

Rose, D. and E. Harrison (eds) (2010), Social Class in Europe: An Introduction to the European Socio-Economic Classification. London: Routledge.

Russell Group (2011), Informed Choices. http://www.russellgroup.ac.uk/informed-choices/. [Last accessed on 22 April 2014]. 
Van de Werfhorst, H. G., Sullivan, A. and S. Y. Cheung (2003), 'Social Class, Ability and Choice of Subject in Secondary and Tertiary Education in Britain.', British Educational Research Journal, 29(1), 41-62. 
${ }^{1}$ From the school year 2013/14 onwards new qualifications, called Nationals 3, 4 and 5, replaced Standard Grades.

${ }^{2}$ Since the Irish survey is a leaver survey rather than a cohort survey, Irish students leave lower secondary education at different points in time so we cannot analyse the transition from lower-secondary to uppersecondary education in both countries.

${ }^{3}$ Given the count data nature of our dependent variable, we replicated our analyses with Poisson regressions and Negative Binomial regressions (to test for overdispersion) for both sexes, models and all cohorts. The marginal effects at the means are similar to our OLS regression coefficients in all cases. Since patterns are identical, for simplicity we present the results from the OLS regression analyses. 